\title{
Thou Shalt Not Think: Editors' Voice in an English Textbook to Propagate Vested Agendas
}

\author{
Jabreel Asghar \\ English Language Institute, King Abdulaziz University, P.O. Box 80200, Jeddah 21589, Saudi Arabia \\ Correspondence should be addressed to Jabreel Asghar; jabreel@hotmail.co.uk
}

Received 21 April 2014; Revised 25 May 2014; Accepted 11 July 2014; Published 24 July 2014

Academic Editor: Cathy H. Qi

Copyright ( 2014 Jabreel Asghar. This is an open access article distributed under the Creative Commons Attribution License, which permits unrestricted use, distribution, and reproduction in any medium, provided the original work is properly cited.

\begin{abstract}
Textbooks, particularly in developing countries, are used as a tool to propagate the agendas of state and other groups in power. This paper informs the reader on the issue of how a tertiary level English textbook used editors' voice to form the opinion of its readers by shaping facts and perspectives depicted in the texts. The editors of the textbook not only censored the information to block autonomous learning, but also attempted to misrepresent the themes of various texts to meet the censorship guidelines set by the textbook-board and/or the state. The paper aims to raise the question of learner autonomy and learners' right to access information in its original form to be interpreted independently in the schematic background of each individual. By pointing out the issue and initiating the discussion, the paper hopes to bring awareness in the less explored area of the use of language power in the Pakistani educational context.
\end{abstract}

\section{Introduction}

Textbooks have a central role in educational setting and are considered an essential tool to achieve the learning goals. This status has given substantial significance to textbook as a learning tool, due to which greater care is required while selecting and designing the contents, structure, and layout of textbooks in order to suit learning needs and goals. Apart from catering to learners' interests and learning needs, the texts and the selection of texts may have a hidden agenda to promote the desired ideologies of various sections of a society and state. Such a dimension of textbooks also accentuates the power of education which a state or certain group/s may exploit by controlling the learning materials and hence minds of people. This paper specifically refers to the controlling power of involved groups in developing a textbook [1] by analysing the predetermined and moulded message of texts embedded in a follow-up section titled as "Theme" written by the editors of the book. The purpose of this section in the textbook is to inform learners of the main idea of the text and other related information essential to understand the texts. However, the editors of the textbook have taken this opportunity to propagate certain notions, misleading students' understanding of the texts towards false or inaccurate perception of the world. This paper uncovers this particular aspect of misusing the language power to serve vested interest of certain individuals and/or groups to intentionally or unintentionally shape the desired ideologies among students at a stage which is significant in forming their own view of the world.

\section{Related Literature}

Discourse structures create power relations in terms of how we negotiate our relative status through interchange with others [2]. Fairclough [3] and Fairclough and Wodak [4] view language as having two versions of power: power in discourse and power behind discourse. By the former they mean the power which appears in lexical choices and syntactical structures, for example, directive speech acts, imperatives, and so forth. The latter includes power behind discourse where the whole social order of discourse is put and held together as a hidden effect of power, for example, the hidden power of media discourse to influence/change [3].

Considering the same power of discourse, Liu [5] asserts that the purpose of textbooks does not remain to pursue a particular curriculum only, but also to embody particular 
constructions of social world. Liu maintains that closed discourses are important in almost all Asian educational contexts where textbooks are used as a means of propagating certain political notions. Their aim is not to develop better human beings but better followers of a particular political and/or economic agenda. If the texts offer closed discourses different from the readers' own living environment and social reality, they would "encounter a kind of contradiction or ideological shock" [5, page 259]. In order to avoid this shock, Liu suggests to present ideological tensions and competing discourses as they are, rather than deliberately regulating or excluding certain features. Liu raises the question of closed discourses which is imperative in almost all Asian educational contexts where textbooks are used as a means of propagating certain political notions.

Phillipson [6] is also of the view that textbooks can be used as a tool of propaganda by certain groups. He refers to the promotion of the British global course book as a government-backed enterprise with an economic and ideological agenda aimed ultimately at boosting commerce and the dissemination of ideas. In this regard, he views the ELT course book from an ambassadorial perspective. He is convinced that teachers add, delete, or modify texts, tasks, and activities to suit learners' needs and students accept these reinterpretations. Gray [7] identifies a number of areas where cultural content is often reshaped (or censored) by teachers. In other words, teachers edit the texts which they think are culturally inappropriate for their learners or misrepresent a group or individual. Gray advocates a cross-cultural approach, where students are encouraged to make comparisons between their own culture and those represented in the course book. Therefore, Gray proposes to empower learners by making them more independent in the learning process. In a similar way, this paper recommends a critical dimension to be added to the curriculum.

Coratzzi and Jinn [8, page 200] assert that a "textbook is seen as an authority and can also be viewed as an ideology in the sense that it reflects a worldview or cultural system, a social construction that may be imposed on teachers and students and that indirectly constructs their view of a culture." They further elaborate that in analyses, there may be an identifiable interest-based perspective, which is explored by such questions as in whose interest is this text written and why. Ndura [9] highlights three major biases in the textbooks, that is, stereotyping, omission of information, and unreality. She asserts that students get one-sided information through such biased textbooks. It denotes that students should be made aware of biases in the texts and they should be trained to critically read their textbooks rather than given censored texts to encourage a stereotype philosophy. Providing learners with opportunities to enjoy the ownership of their learning process is most likely to empower them.

\section{The National Curriculum of English Language in Pakistan}

The National Curriculum of English Language, the NCEL [10], is a policy document prepared by the official committee that determines the learning goals and outcome in alignment with the overall learning process from grade 1 to grade 12 . It will be useful to give an overview of the document to help the readers of this paper to understand the background where the textbook is being used. Referring to the overall learning outcome for the users of the textbook at hand, Asghar [1] summarizes the major goals for the same texts in the National Curriculum of English Language. Some of the major goals include character building, respect for Pakistani values and those of other nations, tolerance, humanism, equity between groups and nations, understanding international cultural diversity, understanding the world, respect for all professions by valuing disparity, and equality among professions. At academic and linguistic level, the NCEL prescribes five competencies to be achieved at the end of the course. These competencies cover the areas of skills in reading, thinking, and writing, oral communications and development of formal and lexical aspects of language, and ethical and social development [10, pages 120-142]. As the discussion below would demonstrate, almost all of these competencies are violated due to careless exploitation of language use. Asghar [11] also points out that these texts, along with the themes, have not only been presented with a biased overview of certain professions and nationalities, but they have also utterly failed in having learners identify social, geographical, and cultural differences as portrayed in the texts; hence the NCEL failed in developing a global approach to humanity, multiculturalism, and tolerance towards other nations.

The state policy for curriculum development in Pakistan can be summarised as preparing human beings in the light of Islamic teachings to become good Muslims and proud Pakistanis. This is the basic stone of all the educational policies introduced in the history of Pakistan. There is no exception even in the last martial regime of 2001-2008 which is notoriously known for enlightened policies in all walks of life including education. Afzal [12] refers to a report presented at the Jinnah Institute in Pakistan, which argues that the 2006 curriculum violates Pakistan's Constitution by forcibly teaching Islamic studies to non-Muslim students. This is because the curriculum explicitly requires that Islamic teachings be taught in Urdu and General Knowledge classes. The report argues that the new textbooks go even further than the curriculum dictates, by teaching Islam in English class textbooks as well. On the other hand, the NCEL, in its introduction and philosophy statement claims that the curriculum has been developed to

(i) provide language learning and teaching experiences within national and cultural bounds while encouraging the learners to be autonomous and lifelong learners;

(ii) equip (learners) with competencies in using the English language for communication in academic and social contexts;

(iii) enable (learners) to be autonomous and lifelong learners to better adapt to the ever changing local and world society and to knowledge advancement; 
(iv) serve as a guide for teachers, learners, textbook developers, assessors, and all other users;

(v) promote the academic and employment language needs for learners who wish to pursue their higher studies, as well as for those who might terminate education after grade XII.

(See [12, pages 1-2]).

Ironically, the NCEL does not use the word Islam, the Quran, or Muslim even once in the 184-page long document, which seems to suggest an explicit deviation from the basic stone of educational policy as well as the foundation of the constitution of 1973 of Pakistan. However, as the analysis below would demonstrate, such a so-called secular curriculum could not facilitate developing textbooks which could fulfill the goals and objectives. Censorship due to religious and cultural constraints has been a part and parcel of publishing in the third world countries, and Pakistan is not an exception. The NCEL, though, does not show any religious fervour in the document; the texts in the textbook in question contain frequent examples of censorship. This shows that not only is there lack of alignment between the state policy and the curriculum philosophy, but there are also missing connections between the goals set by the NCEL and development of textbooks to achieve these goals, where the textbooks editors, contrary to the NCEL, seem to censor the texts as a result of an undocumented policy. The NCEL claims to have provided detailed instructions and guidelines for teachers and textbook developers. However, it appears that there was no further consideration beyond these guidelines due to which the textbooks seemingly contain materials in sharp contrast with the NCEL philosophy of curriculum development.

\section{Research Data and Related Information}

This study analyses an English textbook titled English Book-1 [1] taught at higher secondary level in Pakistani state colleges in the province of Punjab. Generally, the textbooks at higher secondary and bachelor level are prescribed by the respective provincial textbook board that appoints professionals to recommend texts to be included in the book. The panel of editors selects texts, invites nominated experts, and approves the pedagogic activities for each text suggested by these experts. These textbooks do not contain any teacher manual. Teachers usually translate and summarise each text in the class followed by completing grammar based gap-filling and comprehension tasks prescribed in the textbook.

4.1. The Textbook. Out of three textbooks at higher secondary level in Pakistani state colleges, the textbook in question is the students' first interaction with a so-called authentic English text when they join a college for the first time after ten years of education at school. Therefore, this textbook is of vital importance to impact learners' perception and contribute to their learning procedure as well as learning outcome. The genre of short stories is considered an effective means to communicate the message more articulately. Thus the textbook in question being comprised of short stories from literature is potentially a vibrant source of inspiration for learners. In this perspective, this textbook seems to be more central to the learning process in the sense that the learners are likely to build up their experience based on what they acquired and aspired from these texts.

The audience of this textbook consists of males and females, roughly 17-19 years old. Since the textbook is taught in state colleges, the background of these learners may slightly vary but generally a vast majority of them belong to middle and lower middle class of society. The upper class tends to go for A levels examination which is based on an entirely different syllabus from that of mainstream state colleges. The textbook is taught in the eleventh academic year to the students who have been studying English as a compulsory subject since their first year at school. However, despite the fact that their exposure to English language is spread over more than a decade, they cannot be considered competent users of the language due to various factors, for example, outdated syllabus, conservative teaching strategies and teaching quality, and traditional curriculum not addressing the demands of rapidly changing needs of learners in the 21st century. The teaching methodology is mainly teacher centred and classrooms more or less present a picture of traditional grammar-translation based approach, explicitly discouraging critical thinking and autonomous learning.

4.2. Analytical Framework. The analytical framework of this study is comprised of two levels. At theoretical level, the framework is partly influenced by Foucault's [13] approach to discourse analysis. Foucault views discourse as practice and system of representation. While referring to analytical approaches to language, he argues that it is not the expression itself but the rules which make a text discursively meaningful. He states that it is not the syntax and semantics that determine the discursive meaning of a text. He also believes that meaningless letters might have discursive meanings and grammatically accurate phrases might lack discursive meaning. The notion of power relationships is of focal significance in Foucault's approach to discourse analysis. According to Wooffitt [14], the analysis under Foucault's approach attempts to understand how individuals view the world and studies categorizations, personal and institutional relationships, ideology, and politics. Assuming Foucault's analytical approach to discourses to be an essential theoretical component of analytical framework, this study analyses the themes of the textbook, taking into account the discursive meanings of the texts without heavily relying on the syntactical choices. The analytical approach in this study is keenly concerned with exploring power relationships created by the text producers. The analysis also aims to understand the extent to which the themes may enable their readers to form their own worldview in relation to their ideologies and institutional relationships.

At interpretative level, the study takes into account positioning of point of view to analyse the themes using $\mathrm{M}$. Bloor and T. Bloor's [15] stance which they consider to be natural on the writer/speaker's part; also one of the main jobs of analysts is to recognise the stance. M. Bloor and T. Bloor also believe that, in most contexts, writers take advantage 
of conventions of fact, opinion, objectivity, and bias. Writers present their ideas according to these conventions of the particular discourse as the writers of the themes seem to practise in this case. There is also a tenor dimension in the analysis of the themes because it is written to the readersstudents and teachers in this case. In this perspective, the analysis looks into the texts of the themes at word and phrase level where connotation and choices of particular words and phrases might be significant to express degrees of certainty and attitude of the writers [16, page 185].

The analysis also takes into consideration the representation of the writers, their identities, and authority in their written texts as voiced in the language of the themes, reflecting the sociocultural aspect of the writer's background. Writing in this perspective becomes a social activity in which writers align themselves in acceptable discourses to express themselves by reinventing ideas and linguistic expressions created by others [16]. The analysis from this angle exposes how the writers of the themes have used their voice as a tool to propagate their vested agenda and disempowered learners.

\section{The Analysis}

In the themes section, the writer appears to allegedly comment on the contents of the short stories by taking an overt and may be unconscious stance most probably in order to represent the ideologies as well as policy of the curriculum developers and hence that of the state. In five texts (Button Button, Clearing the Sky, Dark they were and Golden-eyed, Thank you Ma'am, The Foolish Quack, and A Mild attack of Locusts) the themes summarise the text in plain words without giving any in-depth vision of the texts. It does not discuss the authors as it discusses in other themes where introduction to the authors is made separately followed by the theme.

Themes of all the texts do not necessarily give the central idea of the texts but a simple summary. This summary in many cases does not serve to summarise the text but rather to suggest conclusions and judgments as follows.

(1) Norma, overcame by the temptation, pushed the button in the absence of her husband and got him killed in an accident (Button Button).

(2) The boy became very much impressed by the good conduct of the lady and promised to be a good boy (Thank you Ma'am).

(3) The use of force in certain cases, when sick children resist to get themselves examined becomes necessary to save their lives (The Use of Force).

(4) What is good for camels is not good for old men and women (The foolish Quack).

(5) The story reveals that exchange of gifts on the holy occasions makes life most lovable (The Gift of the Magi).

Rather than having learners deduct meaning themselves, the above type of guidance seems similar to spoon feeding with the intention of propagating the desired or censored version of the theme (Table 1). For example, in quote (1) above, the editors have explicitly blamed Norma for the tragedy, which is only a superficial perception. A number of other interpretations are possible which have been simply denied by the editors. In quote (2) above, the editors straightaway presented their predetermined moral that merely the good conduct changed the boy. The whole emphasis is on the product, that is, the transformation itself without any concern with the process of transformation, which might not be genuine or temporary in the first instance, or might well have included several other complex psychological factors, such as feelings of fear, guilt, or mere pretention, leading to the transformation of the boy. The editors blocked all these realistic, practical, intellectual, and philosophical possibilities by rushing to a moral conclusion.

Some of these morals are not logical or relevant in the above examples. For example the suggested moral of (3) above is too narrow to justify the use of force in "certain" circumstances. It is arguable to define the level of certainty. The text activities or the theme does not encourage defining that "certainty." It seems to give no individuality to children, by simply obeying to the desires of adults. The authority of using force may communicate a wrong message to learners to use force whenever they feel it is inevitable. Such an understanding may well provide with the logic of corporal punishment to many individuals. The moral of (4) might be considered ridiculous, rather than humorous, which makes illogical comparison between camel and men instead of highlighting the drawbacks of ignorance and lawlessness in society. Instead of getting the learners' attention towards the serious consequences of ignorance, it illogically suggests to treat human being differently from camels.

The moral of (5) also seems to be "forced" when, instead of highlighting the passionate conjugal love, it refers to exchanging of gifts on holy occasions as a mark of love. By focusing on the "holiness" of the occasion and ignoring the conjugal life and the passion of love between husband and wife, the theme seems to suggest a censored version of the text by exploiting religious feelings of learners to persuade them. An impartial reader of the same text is most unlikely to infer the same message as suggested by the writers of the theme. The effort of the theme-writers to divert the meaning is most probably due to the prevalent social norm in the Pakistani society which does not appreciate discussing the emotions of conjugal life with young people and especially with girls. Twisting the meaning of these texts raises issues of honesty in communication. There are other similar examples of censored versions of the texts to create "an appropriate" impression to the society. In this respect, Asghar [11] pointed out that almost all the texts in this textbook are censored and/or abridged versions of the original texts. For example, one of the texts "God be Praised" is originally a delicate satire on dual standards of society as well as overpopulation. However, the text has been edited in a way as to diminish this impression. Another text "Overcoat" has reference to a young couple without explicitly referring to a legitimate relation, which has been excluded from the text.

Though a public document such as a piece of literature is open for any individual interpretation, it does raise the question of whether it is fair to twist someone else's work to 
TABLE 1: Summary of short stories in the textbook [11, page 405].

Foreign Texts (FT)

(1) Button Button

(2) Clearing in the Sky

(3) Dark they were and Golden-Eyed

(4) Thank you Ma'am

(5) The Piece of String

(6) The Reward

(7) I Have a Dream

(8) The Use of Force

(9) The Gift of the Magi

(10) The Angel and the Author-and Others

(11) The Gulistan of Sa'adi

(12) The Foolish Quack

(13) A Mild Attack of Locusts

(14) God be Praised

(15) Overcoat
A couple comes across an offer of a getting a big amount for pressing a button, which would result in killing a person somewhere in the world. The wife accepts the offer and gets insurance of her husband who apparently dies as a result of pressing the button.

A father narrates to his son how sheer out of his dedication and hard work he cultivated a piece of land at a very difficult mountainous location.

The earth has been destroyed and the mankind has started a new life on Mars. One man keeps trying to go back to the earth despite the opposition of everyone, but one day decides to stay where he is.

A woman treats a child with love and affection who tried to snatch her handbag to buy suede shoes.

A poor villager is falsely accused of stealing money. He spends all his life in clarifying his position but nobody believes in him until after a flood sweeps away everything except his grave.

A boy wants to be an acrobat and is successful in achieving his goals after consistent efforts and after facing a lot of difficulties.

An abridged version of Martin Luther King's speech about freedom and equality for all mankind.

A sick child is not willing to let the doctor examine her throat. The doctor has to use force to examine the child's throat and prescribe the medication.

A poor young girl sells her beautiful hair to buy a strap of watch which was the most valuable asset of her husband. On the other hand, the husband sells the same watch in order to buy golden hair clips for his wife.

At a Christmas Eve, the writer humorously and sarcastically talks to the Recording Angel about the details of his trivial acts of charity in order to be rewarded hereafter.

Local Literature

Short stories in classical Iranian context to highlight wisdom of everyday life.

A foolish villager tries to treat people without using common sense and receives punishment by people after killing sick woman.

Apparently in a colonial context, a white family, with the help of local population, tries to save the crops from the attack of locusts. They could not save them completely but still they are contented that they could save some part of their assets.

A poor clergyman finds it hard to keep both ends meet. He spends whole of his life expecting God to sort out his difficulties, especially the marriage of his daughters. Apparently it seems to happen.

A well-dressed young man meets his end while he was strolling on the mall. During his postpartum, it was discovered that under his precious overcoat he was in rags. serve the vested interest of an individual or a group. It may be interrogated if it is appreciable to draw morals out of texts the way they were never meant by the author/s or by an average impartial reader of the member of similar social group.

These themes also do not seem to significantly contribute to the understanding of the texts because they do not help learners develop better understanding of human psychology and social life-one of the major purposes of reading literature. These themes could have been used more effectively by providing thoughtful insight and generating discussion in the class. I presume that this kind of discussion on English literature has been avoided intentionally at this level where learners are believed to be too young (17-19 years old) to be shared issues on various aspects of life and particularly on the emotional side of life. It is generally believed in Pakistani society that teenagers need to be told what to do and how to do it. This is what the themes in this book seem to strive for. Various cultural differences such as equality or dominance of female characters in Button Button and Dark they were and Golden-Eyed present a sharp contrast with the extremely submissive nature of female characters in God be praised, Gulsitan of Sa'di, and to some extent in Overcoat. Such diversity potentially generates difference of opinion and hence useful discussion in the immediate context of the learners. However, in the Pakistani culture, difference of opinion is viewed as something of disrespect and disobedience. It is not encouraged even in the mainstream academic context where students are supposed to adhere to teachers' verdict. Students' individual opinion is regarded as immature and inexperienced. That might be another reason why the themes seem to suggest certain morals explicitly and straightforwardly rather than raising questions for discussion.

The theme of God be Praised does not explain the issues of the text in depth but only mentions the issues of marriage of girls casually. It might be due to the reason that it is an abridged as well as censored version of the original text. I used the word "censored" because the original text has delicate satire on overpopulation and family planning issues which are controversial in the Pakistani society and which have been censored in the textbook. The editors have also censored the dialogues and comments which are, though decently, 
romantic. On the other hand the editor's reference to the main religious character in the theme seems to be rather derogatory:

\section{In this story he has depicted the life of a village Maulvi and his miseries... (God be Praised).}

Addressing a religious leader only as "Maulvi" is considered derogatory in the Pakistani social scenario. Such a title is rather used to ridicule someone who is negatively conservative and rigid. One of the goals of the NCEL [10] is to develop respect for all professions among learners. Such a derogatory reference to a profession is in sharp contrast with this goal. Even if this choice is unintentional, lexical choices are significant to carry and convey the hidden ideologies of the writer. The same might be the case in this instance.

The contents of the theme section also reflect the editors' priority in terms of projecting some authors more than the other. In some of the texts, the editors have included introductions to the authors of the texts. The introductions to almost all the foreign writers are detailed, with a brief life history of the writers and their major works. However, talking about Pakistani authors, the editors make very brief comments such as follows.

\section{Ahmad Nadeem Qasmi is a poet and writer of National repute. He was born in a small village of Anga in Sargodha District (God be Praised).}

Ghulam Abbas was born in 1909. He got associated with Radio and also worked for the BBC in London for several years. He earned a lasting reputation as a story writer. He died of heart attack in November 1982 (Overcoat).

Ironically learners have much less to read about the local writers than they read about foreign writers. Ahmad Nadeem Qasmi is one of the legendry Urdu writers. The learners may need to know more about his work and intellectual achievements than his birth place. Similarly in the latter case, Ghulam Abbas' reputation is as a great short-story writer, but the editors focus on his working at the BBC. Out of a 40 -word description, only 10 words have been specified to his literary achievements. Such a stance on introducing local authors with less significance reflects the editors' partiality, most probably rooted in colonial memories as reflected in the second example above where Ghulam Abbas is attributed mainly because of his association with the BBC. Such gestures also convey a negative connotation and at the same time discouraging and intimidating gesture for local readers who are forced to view local writers with minimal status as compared to the foreign authors who are presented with details of the awards and achievements they received.

\section{Discussion}

An overview of the "themes" shows that the curriculum developers have taken this opportunity to teach certain ideologies and morals by shaping the facts and the main ideas of the texts. Such sections in a textbook are supposed to articulate the theme of the texts for learners rather than passing judgments on issues and topics, leading to wishful conclusions, which are at times away from reality. This confirms Liu's [5] stance that closed discourses are important in almost all Asian educational contexts where textbooks are used as a means of propagating certain political notions.

In another study of this textbook by Asghar [11], the readers (students) of the textbook in question are informed that these themes which are always read in the class are very helpful to understand a text. This denotes the students' and teachers' heavy reliance on these notes as guidelines to decode the message in the texts. The themes in most cases have been used to deduct morals from the text which is clearly evident from the responses of students who used the sole criteria of morality to approve or disapprove of any text or character. However, [11] this lacks students' detailed and focused responses on the section of themes, and this limitation highlights the scope of further research to separately explore how students perceive, decode, and respond to these predetermined interpretations of the texts.

Contrary to the broader goals and objectives set by the national curriculum, these themes seem to block independent and critical thinking among learners by imposing guidelines to interpret a text. This section could have been used to provide learners as well as teachers with better ideas to understand the texts by challenging their intellectual and critical skills instead of suggesting morals and verdicts which are not true in most cases.

The NCEL specifies "respect for Pakistani values and those of other nations as well as tolerance, humanism, equity between groups and nations" as its major objectives for the learners of this textbook ([10], pages 145-9). These objectives are fairly realistic but NCEL seems to aim at developing such a balance through means which are highly controversial and conflicting in the Pakistani society, that is, through so-called harmonization of eastern and western values in the name of developing cultural tolerance. Such an attempt may well give rise to confusion among learners who find one set of values in their social life and are exposed to another set of values in their academic context which in many cases might be even opposite to the prevalent social norms. In order to fill this wide gulf, in the textbook, the "Theme" section at the end of each text seems to strive to have the learners deduct the enforced meanings from the texts. Such an approach does not allow learners to perceive the outer world in a natural way but rather it presents things through the eyes of the editors of the textbook and in the long run most probably through the viewpoint of the state. Such a practice confirms that if the texts offer closed discourses different from the readers' own living environment and social reality, they would "encounter a kind of contradiction or ideological shock" [5, page 259]. Most probably, for the same reasons, Asghar [11] inferred that the readers of this textbook could not clearly identify themselves with many of the texts and characters.

Teachers' interpretation of the texts is also likely to compound the issue at hand. Some critics (e.g., [17-19]) believe that textbooks and curriculum guides present messages about what is most important for students to learn and how students can best learn this. However, the curriculum developers are 
not often aware of these messages and consequently ignore these inherent messages without a planned, thoughtful, and careful analysis [17], which we find rather inevitable to understand new knowledge for individual interpretation as autonomous and responsible learners. The editors of the textbook at hand seem to guide students and teachers, in decoding the hidden messages, but, unfortunately, they offer highly adjudicated information leaving no room for teachers and students to deviate from. It is understandable that policy makers might be conscious of teachers' lack of training in identifying and interpreting the messages, but this lacking on teachers' part does not validate a universal action for a population of teachers and students who belong to immensely varied social, cultural, economic, and academic background. Such a diverse background even strongly emphasizes having the users of the textbook perceive the texts in a more personalized context. Otherwise such a gesture on editors' part is most likely to block the intellectual endeavour of the users of the textbooks who otherwise are likely to have as varied interpretations and overviews of the issues presented in the texts as many individuals are exposed to the textbook.

The above discussion demonstrates that the textbook in question seems to propagate a predetermined agenda by combining open discourses of literature with the closed discourses of the "themes." Propagating certain philosophies might be acceptable within the limitation of a state's policies. However, such a liberty should not authorize anyone to impose the forced meanings of the texts on learners. Such a gesture, either from a group or an individual, disempowers the suppressed class-learners in this case. This is a situation where critical pedagogy might be considered to offer potential solutions because it has the capacity to addresses and deal with such types of conflicts within a society.

By adding commentary on the text in the "Theme" section from a certain view point, the textbook does not develop better understanding of the texts but better followers of a particular political and economic agenda. In order to emancipate the suppressed class of learners, teachers, and consequently the builders of future, Liu [5] emphasizes including critical literacy and critical discourse analysis in the educational context which, we believe, is important in Asian countries such as Pakistan. In line with Liu [5], we believe that raising awareness about critical literacy and its role in Pakistani educational context is important so that the Pakistani curriculum could develop better human beings, rooted in their cultural identities with a better understanding of global cultures, and not merely better followers to fulfill a predetermined agenda by the state or certain groups with vested interests.

Considering the state policy for education, the curriculum developers' approach to design a balanced curriculum in line with latest research about learning and teaching approach to prepare learners for the requirement of 21st century, it is high time to consider a shift in pedagogical stance. Keeping in view the extremely varied cultural, economic, sectarian, and geographical circumstances, critical pedagogy might be a good alternative which emphasizes contextual significance and immediate life experiences of learners to be taken into account. Kubota [20] refers that critical multiculturalism which addresses issues such as race, gender, and class in greater depth has an intellectual alliance with critical pedagogy while aiming to raise students' consciousness about unjust social practices and helps them to become active agents of social change. Asghar [21] also proposes to consider Canagarajah [22] who asserts that, learning a second language, learners' membership of their vernacular communities should be addressed in order to "consider how learners negotiate competing subject positions in conflicting discourse communities and how these struggles shape their practices of language learning" [22, page 117]. In this perspective critical pedagogy might be one of the best tools to bring awareness among the members of Pakistani society as Morgan [23, page 16] believes that schools play significant role for struggle and "in one stage of this struggle students are to be developed as fully conscious, rational individuals with a meta-level understanding of language and politics and their roles as subjects."

\section{Final Word}

In the textbook in question, though the texts are open discourses and manifested as they are, editors' notes at the end of each text, in the form of "Theme," regulate or exclude the factors decoding of which could have developed critical thinking among learners. The paper has highlighted how "Themes" at the end of each text in the textbook twist certain facts into "desirable morals" which might not be naturally inferred otherwise. The editors seem to use language as a means of propaganda by giving formed information to guide learners' thinking. Such a misuse of language power deprives learners of thinking independently and perceiving the world in the perspective of their own knowledge and thus must be carefully watched in textbooks.

In this respect, this paper attempts to raise an important, but highly neglected, pedagogical aspect in the Pakistani educational context where textbooks seem to have been used as a propaganda tool to preach predetermined agendas. The paper has maintained a stance that such an approach not only deprives learners of independent and critical thinking but also places students at disadvantageous position as human beings where they cannot form their own worldview but only what they have been forced to perceive. In the case of the textbook at hand, such a standpoint has been forced explicitly by giving limited interpretations of the texts and implicitly by forcing learners to be assessed only through those prescribed interpretations. Insignificant amount of work has been done in this area to raise awareness of teachers' and students' becoming mouthpiece of policy makers. This paper initiates the topic in this regard, inviting further discussion and research in the same direction. The study also emphasizes the need for analysing textbooks on the same line as to what contexts curriculum developers have manipulated the language as a powerful tool to influence users' opinions and identities. At microlevel, the study also intends to raise awareness among teachers and students to be watchful of such guile as has been used by the editors of the textbook at hand in order to beware of unconsciously becoming 
a tool of self-exploitation. In this regard, critical reading and critical thinking skills become increasingly important to uncover hidden ideologies in texts before becoming a victimized follower of hidden agendas of certain groups and/or individuals.

\section{Conflict of Interests}

The author declares that there is no conflict of interests regarding the publication of this paper.

\section{References}

[1] English Book-1 for Intermediate Classes, Punjab Textbook Board, Lahore, Pakistan, 2006.

[2] L. Thomas, S. Wareing, I. Singh, J. S. Peccei, J. Thornborrow, and J. Jones, Language, Society and Power, Rutledge, London, UK, 2004.

[3] N. Fairclough, Language and Power, Longman, New York, NY, USA, 1992.

[4] N. Fairclough and E. Wodak, "Critical discourse analysis," in Discourse Analysis, P. Paltridge, Ed., Continuum, London, UK, 2006.

[5] Y. Liu, "Discourse, cultural knowledge and ideology: a critical analysis of Chinese language textbooks," Pedagogy, Culture and Society, vol. 13, no. 2, pp. 233-264, 2005.

[6] R. Phillipson, Linguistic Imperialism, Oxford University Press, New York, NY, USA, 1992.

[7] J. Gray, "The ELT course book as cultural artifact: how teachers censor and adapt," ELT Journal, vol. 54, no. 3, pp. 274-283, 1992.

[8] M. Coratzzi and L. Jinn, "Cultural mirrors materials and methods in EFL classroom," in Culture in Second Language Teaching and Learning, E. Hinkle, Ed., pp. 149-176, Cambridge University Press, Cambridge, Mass, USA, 1999.

[9] E. Ndura, "ESL and cultural bias: an analysis of elementary through high school textbooks in Western United States of America," Language, Culture and Curriculum, vol. 17, no. 2, pp. 143-153, 2004.

[10] National Curriculum for English Language (Grades I-XII), "Government of Pakistan,Ministry of Education," 2010, http:// www.moe.gov.pk/Curriculum.htm.

[11] J. Asghar, "Change for the better: an evaluative study of a textbook," Language, Individual and Society, vol. 7, no. 1, pp. 404-422, 2013.

[12] M. Afzal, A Failed Curriculum Reform, 2014, http://www .brookings.edu/research/opinions/2014/01/15-pakistan-curriculum-reform-afzal.

[13] M. Foucault, The Archaeology of Knowledge, Tavistock, London, UK, 1972, translated by A. M. Sheridan Smith.

[14] R. Wooffitt, Conversation Analysis and Discourse Analysis: A Comparative and Critical Introduction, SAGE, 2005.

[15] M. Bloor and T. Bloor, The Practice of Critical Discourse Analysis: An Introduction, Hodder Arnolds, London, UK, 2007.

[16] B. Paltridge, Discourse Analysis, Continuum, London, UK, 2006.

[17] E. P. Goldenberg, "Principles, art, and craft in curriculum design: the case of Connected Geometry," International Journal of Computers for Mathematical Learning, vol. 4, no. 2, pp. 191$224,1999$.
[18] H. C. Hill, "Policy is not enough: language and the interpretation of state standards," The American Educational Research Journal, vol. 38, no. 2, pp. 289-318, 2001.

[19] J. P. Spillane, B. J. Reiser, and T. Reimer, "Policy implementation and cognition: Reframing and refocusing implementation research," Review of Educational Research, vol. 72, no. 3, pp. 387431, 2002.

[20] R. Kubota, "Critical multiculturalism and second language education," in Critical Pedagogies and Language Learning, B. Norton and K. Toohey, Eds., pp. 30-52, Cambridge University Press, Cambridge, Mass, USA, 2004.

[21] J. Asghar, "Review of reading goals in the national curriculum of English language (grades 11-12) in Pakistan," Academic International, vol. 5, no. 3, pp. 292-298, 2014.

[22] S. Canagarajah, "Subversive identities, pedagogical safe house, and critical learning," in Critical Pedagogies and Language Learning: An Introduction, B. Norton and K. Toohey, Eds., Cambridge University Press, Cambridge, UK, 2004.

[23] W. Morgan, Critical Literacy in the Classroom: The Art of the Possible, Routledge, London, UK, 1997. 

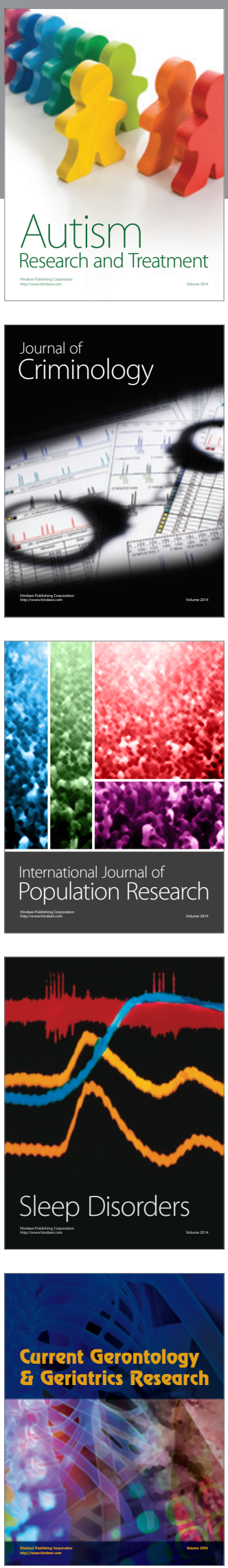


Submit your manuscripts at

http://www.hindawi.com
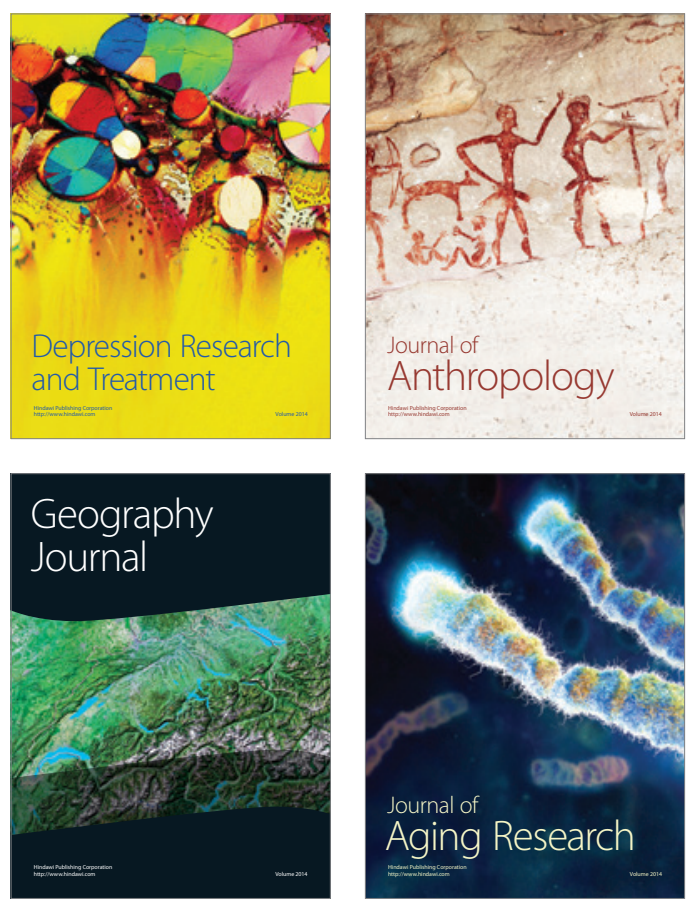
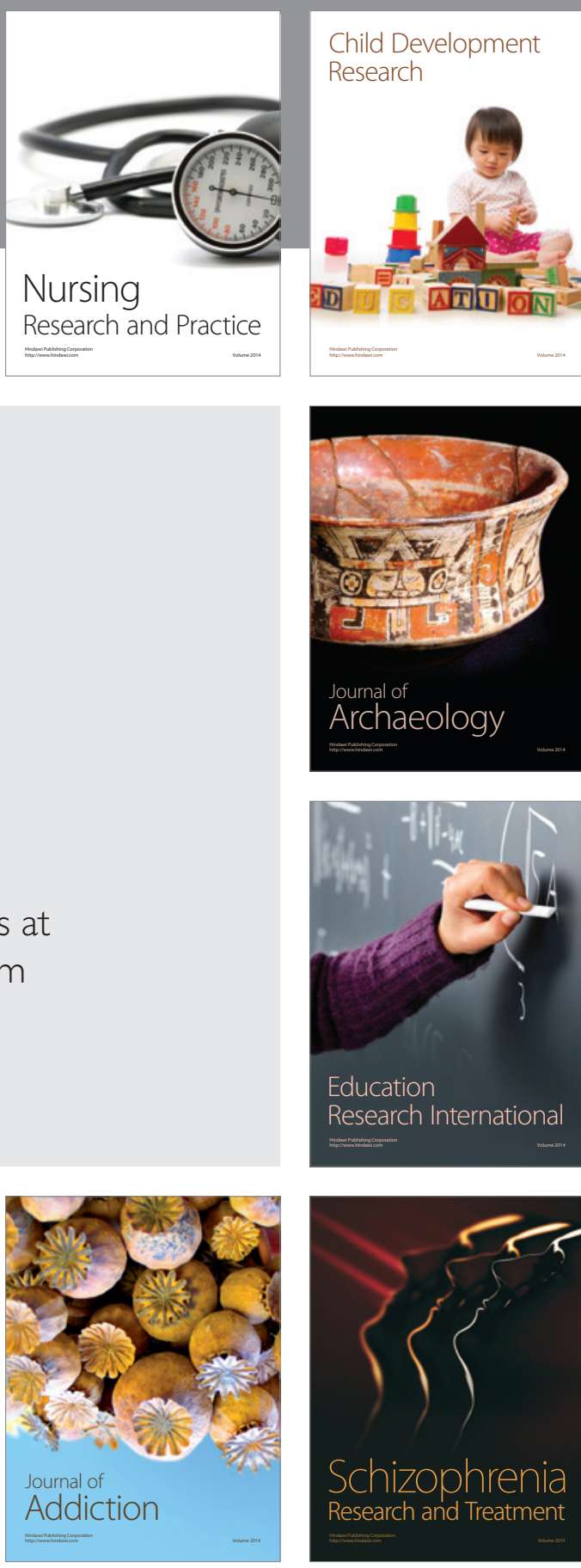

(D)
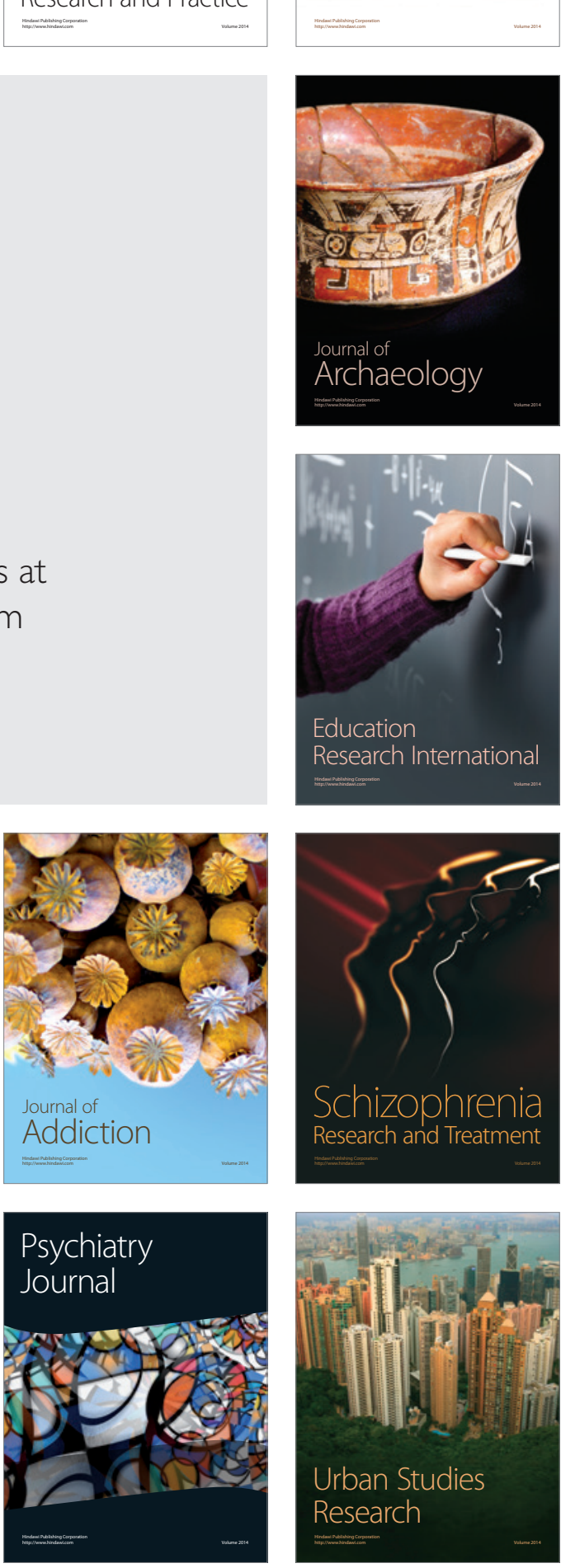